\title{
Caused motion across child languages: a comparison of English, German, and French
}

\author{
Maya HICKMANN ${ }^{1 \star}$, Henriëtte HENDRIKS ${ }^{2}$, Anne-Katharina HARR ${ }^{3}$, \\ and Philippe BONNET ${ }^{4}$ \\ ${ }^{1}$ CNRS \& University Paris 8, France, ${ }^{2}$ University of Cambridge, UK, ${ }^{3}$ Ludwig-Maximilians-Universität, \\ Germany, and ${ }^{4}$ CNRS \& University Paris 5, France \\ ${ }^{*}$ Corresponding author: CNRS, Laboratoire SFL, 59 rue Pouchet, F-75017 Paris, France. \\ E-mail: maya.hickmann@cnrs.fr.
}

(Received 19 December 2016; revised 9 October 2017; accepted 17 April 2018;

first published online 4 June 2018)

\begin{abstract}
Previous research on motion expression indicates that typological properties influence how speakers select and express information in discourse (Slobin, 2004; Talmy, 2000). The present study further addresses this question by examining the expression of caused motion by adults and children (three to ten years) in French (Verb-framed) vs. English and German (Satellite-framed). Participants narrated short animated cartoons showing an agent displacing objects and varying along several dimensions (Path, Manner). A significant increase with age was found in the number of expressed motion components in all languages, as well as an influence of Path (vertical $>$ boundary crossing). However, at all ages, participants encoded more information in English and German than in French, where more variation and structural changes occurred with increasing age. These findings highlight both cognitive and typological factors impacting the expression of caused motion in development. Implications of our findings are sketched in the 'Discussion'.
\end{abstract}

Keywords: caused motion; language development; typological differences; English; German; French

\section{Introduction}

Motion expression has been at the center of much current (psycho)linguistic research (Slobin, 1996, 2004; Talmy, 2000). Cross-linguistic diversity in this domain has led to studies claiming that language impacts how speakers express motion and how they conceptualize motion in discourse. Most studies have focused either on voluntary motion or on placement events but less is known about other types of motion.

This paper examines whether language-specific features also impact children's expression of caused motion ${ }^{1}$ (e.g., events of pushing or rolling objects). Caused

\footnotetext{
${ }^{1}$ This paper distinguishes placement and caused motion events. Placement events may elicit neutral verbs such as put (expressing only the cause of displacement) notwithstanding more specific position verbs in some languages. In contrast, caused motion events elicit the combination of Cause with Manner and/or Path (e.g., push, pull, and [transitive] roll, slide, rentrer (enter)).
}

(c) Cambridge University Press 2018 
motion events are as natural and frequent as other motion events in language, but crucially provide speakers with more choices with respect to the semantic information to be expressed. The problem of organizing the information in discourse is therefore more pronounced. We first summarize relevant language-specific features for voluntary motion and placement events and their impact on adult native speakers, then review studies indicating the impact on how children express motion. Our study compares the expression of caused motion by adults and children across three languages that have different lexicalization patterns: English, German (Satellite-framed languages, hereafter S-languages) and French (Verb-framed language or $V$-language). The aim is to examine how children learn to express caused motion to inform the domain about the properties and development of this still under-researched type of motion event. This will enable generalizations across typological and developmental studies in the light of current research and debates. Results show the impact of Age, Language, and Path on children's productions. The discussion highlights implications for children's spatial language acquisition.

\section{Voluntary motion and placement events across languages}

Talmy (2000) distinguishes language types depending on how they express semantic motion components, defining the core schema for voluntary motion as including: an entity (Figure) located or moving in relation to another entity (Ground), motion per se, the trajectory of motion (Path), and an optional co-event concerning how motion is performed (Manner). S-languages such as English and German (1) typically express Manner of motion in the verb root and Path in satellites (e.g., particles, prepositions), whereas V-languages such as French (2) lexicalize Path in the verb and downplay Manner, which is either relegated to the periphery (e.g., gerunds, prepositional, adverbial expressions) or not expressed at all. As shown in (3) to (5), these systems are relatively productive and can apply to many types of voluntary motion events.

(1) She is running across the street.

(2) Elle traverse la rue en courant.

'She is crossing the street running.'

(3) to run, fly, swim ... up, down, across, into, out of, away ...

(4) $\mathrm{zu}$, hoch, runter, hin, her ... laufen, fliegen, schwimmen ... 'to, upward, downward, away (from origo), to/towards (origo) ... walk, fly, swim ...'

(5) monter, descendre, traverser, entrer, sortir, partir ... en courant, en volant, à la nage ...

'to ascend, descend, cross, enter, exit, leave ... by running, flying, by a swim ...

Since Talmy formulated his typology, many studies have examined its impact on the expression of motion in discourse. Often, these studies involve productions of adult native speakers in free narratives or in experimentally controlled situations (descriptions of pictures, videos, cartoon clips). Findings are extremely robust, showing that lexicalization patterns indeed differ in line with the typological group to which the languages belong. They also show an influence of typology on syntactic patterning (Allen, Özyürek, Kita, Brown, Furman, \& Ishizuka, 2007): S-languages allow for compact packaging of both Manner and Path with Path expressed in 
satellites, leaving the verb free for the expression of Manner. In contrast, since V-languages typically express Path in the verb, they are likely to use less compact packaging (including a subordinate clause expressing Manner) or to distribute information over more than one clause, i.e., using two independent clauses to express Manner and Path. Overall discourse organization is also influenced by these typological differences (Slobin, 2004). For example, S-languages invite speakers to string several Path elements within one clause (e.g., three in He runs over the bridge, across the field and into the barn), whereas in a V-language this typically requires three different verbs across different clauses.

These typological patterns are clearest when the events described involve boundary-crossing rather than motion within a general location (Aske, 1989; Özçalişkan, 2015), a phenomenon known as the 'boundary-crossing constraint'. Thus, crossing and entering/exiting events have a particular status in V-languages because the boundary (Path) is likely to be lexicalized in the verb, whereas it is usually expressed by some other device outside of the verb root in S-languages, irrespective of event type.

Notwithstanding these robust results, research on an increasing number of languages also shows inter- and intra-typological differences, resulting in vivid discussions about the proposed typology itself (Beavers, Levin, \& Tham, 2010; Croft, Barðdal, Hollman, Sotirova, \& Taoka, 2010; Matsumoto, 2003). For example, it has been argued that some languages (e.g., Chinese) do not fit easily in the S vs. V dichotomy and should be viewed as falling on a continuum defined in terms of a gradient of Path or Manner saliency (Ibarretxe-Antuñano, 2009; Ji, Hendriks, \& Hickmann, 2011a; Kopecka, 2006; Slobin, 2004). Similar results are reported for the expression of causation and placement (cf. Bohnemeyer, Enfield, Essegbey, \& Kita, 2011; Gullberg, 2011; Hickmann \& Hendriks, 2006; Kopecka \& Narasimhan, 2012; Majid, Bowerman, van Staden, \& Boster, 2007; Narasimhan \& Brown, 2009; Slobin, Bowerman, Brown, Eisenbeiss, \& Narasimhan, 2011). In addition, in their study of placement events, Slobin et al. (2011) found that four S- and four V-languages showed not only inter-typological but also intra-typological differences, the latter being better explained by the perceptual saliency of morphology and the particular semantics of the verb. Other intra-typological examples are found between German and English: German provides a rich system of particles such as deictic particles (hin/her) indicating direction towards or away from the origo (6), and explicit case markings (7) often indicating whether motion implies a change of location (Accusative) vs. when it takes place within a general location (Dative).

(6) Der Mann zieht den Kinderwagen hinüber.

'The man pulls the pram across [away from speaker].'

(7) Er schiebt den Tisch in die [ACC] Höhle/in der [DAT] Höhle.

'He pushes the table into/inside the cave.'

From a developmental point of view, child language acquisition can be seen as a process that is guided by language-specific features in addition to general cognitive processes. In this context, several studies have examined motion expression to address the question of whether and how language-specific differences impact children's language development and their construal of motion events. 


\section{Voluntary motion and placement events across child languages}

Children's expression of voluntary motion and placement events shows similarities across languages as well as striking cross-linguistic differences. Common developmental change is presumably due to children's increasing cognitive capacities, e.g., when remembering and expressing multiple types of motion information in cohesive and coherent discourse (e.g., Cowan, 2014; Gathercole, 1999; Hickmann, 2003; Lloyd, 1991; Newcombe, Uttal, \& Sauter, 2013; Nys, Gyselinck, \& Hickmann, 2016; Pickering, 2001). Thus, in all languages tested, young children express less information than older children or adults.

Nonetheless, from early on, children follow the same typological constraints as adults with respect to three dimensions: lexicalization patterns (Bowerman, 1996; Bowerman \& Choi, 2001; Choi, 2011; Choi \& Bowerman, 1991; Harr, 2012; Hickmann \& Hendriks, 2010; Hickmann, Hendriks, \& Champaud, 2009a; Hickmann, Taranne, \& Bonnet, 2009b; Naigles, Eisenberg, Kako, Highter, \& McGraw, 1998), overall syntactic patterning (Allen et al., 2007), and discourse organization (Slobin, 2004). Children learning V-languages (French, Spanish, Turkish) tend to focus on Path (e.g., French monter 'to ascend', traverser 'to cross'), while speakers of S-languages (English, German, Dutch) express both Manner (in the verb root) and Path (in satellites) within the same utterance (e.g., English run up, run across). In addition, although Manner + Path utterances increase in most languages, they remain less frequent in V-languages than in S-languages, which show an increase in the use of subordination as a way of adding Manner to Path (e.g., monter en courant 'to ascend by running'). Furthermore, some variation occurs within language type. Thus, in addition to Slobin et al.'s (2011) results discussed above, some research (Harr, 2012; Hickmann \& Hendriks, 2010) shows that children make earlier systematic use of Manner + Path descriptions in German as compared to English. Finally, variation can also occur within each language, as illustrated for example by the fact that English can also express Path in the verb, i.e., 'to leave'.

Previous research also shows that motion expression in child language may vary as a function of event types. In particular, crossing events intrinsically imply a clear boundary and therefore a categorical change from one location to another (e.g., from outside to inside for into or entrer 'to enter'). In contrast, vertical motion implies a gradual change of location with no intrinsic boundary: although it is possible to infer a terminal point, e.g., with monter 'to ascend' (to the top), this boundary is pragmatically inferred from context or world knowledge and is not intrinsic to the semantics of the verb. This feature was shown to impact native adults and children learning their first language (cf. Harr, 2012; Hickmann et al., 2009b).

Several studies have examined spontaneous productions by young children (under five years). Some report that language-specific features impact productions early (from first word productions) (Bowerman, 1996; Choi \& Bowerman, 1991; Hickmann et al., 2009b; Slobin et al., 2011), while others find that children are still tuning into their native language at later ages, i.e., three to four years (Allen et al., 2007). However, all studies have found that despite early language-specific traits, children's language, even at age five, is not entirely adult-like and continues to evolve gradually as they tune into the adult system. Further cross-linguistic studies over large age spans (Hickmann et al., 2009b; Özçalişkan \& Slobin, 1999) are essential to understand the entire developmental process. 


\section{Caused motion in language and in acquisition}

Less is known about typological influences on the expression of caused motion, whether in adults or in children. At the same time, and most importantly for our study, these events involve a larger number of elements from which to choose for expression, e.g., apart from Path, speakers can choose to express Manner of cause (push, pull), Manner of object motion (roll, slide) and/or pure causal displacement (put, make move). As explained in more detail below, this situation is likely to increase the problem of organizing information in discourse and thereby magnify differences and similarities across typological groups.

Although Talmy has worked extensively on the semantics of causation, most of this work focuses on English. His predictions regarding the encoding of caused motion across typologically different languages propose that Cause (like Manner) is a co-event which can be co-expressed by S-languages in the verb together with motion. In contrast, in V-languages such as French, Path is encoded in the verb, thereby raising the question of where Cause will be expressed. Following the reasoning for voluntary motion, one prediction might be that Cause (like Manner) should be expressed in the periphery of the verb. However, since Cause is a central semantic feature of events, another prediction might be that it will be encoded in the verb (e.g., tirer 'to pull', pousser 'to push'). Caused motion situations therefore present V-language speakers with a choice between the typical V-framed pattern and an alternative pattern that involves Cause in the verb and Path elsewhere. Inter-typological differences include the possibility of causative alternation in German and English allowing the same verb form to be used as intransitive (voluntary motion) and as transitive (caused motion), as illustrated in (8) and (9). In French, intransitive Manner verbs can denote spontaneous motion, as in (10), but a periphrastic causative construction such as (11) (faire 'to make' + INF) is often preferred for caused motion in comparison to the transitive use of a Manner verb as in (12).

(8) Der Ball rollt den Berg hinunter.

'The ball rolls down the mountain.'

(9) Felix rollt den Ball den Berg hinunter.

'Felix rolls the ball down the mountain.'

(10) La balle a roulé jusqu'en bas de la colline.

'The ball rolled to the bottom of the hill.'

(11) Il a fait rouler la balle jusqu'en bas de la colline.

Lit: 'He made-roll the ball until the bottom of the hill.'

'He rolled the ball all the way down the hill.'

(12) ?Il a roulé la balle jusqu'en bas de la colline.

'He rolled the ball until the bottom of the hill.'

As already discussed by Allen et al. (2007) for voluntary motion, one obvious extension of these typological properties is that speakers can systematically 'package' more information about caused motion in S-languages than in V-languages. For example, in (13) Manner is encoded in the verb root - denoting either how motion was caused (push) or how the object was made to move (transitive roll, slide), while Path is simultaneously expressed in the periphery (up/down). In comparison, caused motion expression in French is less compact and more varied: given the absence of 
particles, speakers frequently rely on separate verbs across clauses, e.g., (14) and (15). In (16) the verb expresses how motion was caused (pousser 'to push') and an adverbial expression encodes direction (vers le haut 'upward'). French also provides alternative ways of combining these different types of information, such as Path verbs used transitively, as in (17).

(13) He pushed/rolled the ball up/down.

(14) Il pousse la balle et il monte.

'He pushes the ball and he ascends.'

(15) Il monte en poussant la balle.

'He ascends [while] pushing the ball.'

(16) Il pousse la balle vers le haut / vers le bas.

'He pushes the ball upward/downward.'

(17) Il monte le ballon.

'He ascends [transitive] the balloon.'

French causative constructions may be used to combine Cause with various components, including Path (18). Uses of verbs that can combine Cause with Path, however, are partially determined by a number of semantic and pragmatic constraints in context, e.g., (19) is possible with non-human patients while a causative construction is required for humans (20).

(18) Elle a fait monter sa valise au troisième étage.

Lit: 'She made-ascend her suitcase to the third floor.'

'She had her suitcase taken up to the third floor.'

(19) Elle a rentré les chaises / *ses amis avant l'orage.

Lit: 'She entered [transitive] the chairs / *her friends before the storm.'

'She put/took the chairs inside before the storm.'

(20) Elle a fait rentrer ses amis avant l'orage.

Lit: 'She made enter her friends before the storm.'

'She had her friends come inside before the storm.'

Although very few studies are available about the impact of language-specific properties on the expression of caused motion in its acquisition, they show similar influences of both general cognitive and language-specific factors in development (Furman, Kuntay, \& Özyürek, 2014; Hickmann et al., 2009b; Ji, Hendriks, \& Hickmann, 2011a, 2011b). To our knowledge, the present research is the largest cross-linguistic study on the acquisition of caused motion in terms of the number of languages, of age groups, and of participants per age.

\section{Aims and hypotheses}

The present study compares the expression of caused motion by adults and children in English, German, and French. The aim is to further our understanding of the expression of caused motion across languages. More specifically, we aim to determine whether age and language impact the number and types of semantic components expressed, as well as how they are organized within and across clauses. The present study invited participants to express and combine many semantic components in their motion descriptions, raising new questions about how children learn to encode this 
information. For example, since not all motion-relevant information could be readily expressed within a single clause in any of the languages studied, our predictions concerned how many motion components should be selected for expression across languages based on linguistic typological properties. In particular, we expected to observe more components expressed in German and English than in French, more Path expression in French, and fewer components expressed by young children than by older participants. Specifically, the study tested four hypotheses.

First, the number of components expressed was expected to increase with age in all languages, reflecting children's increasing cognitive capacities when encoding multiple types of information about complex events. Second, a language effect was also expected at all ages: speakers should express more motion components in English and German (S-languages) than in French (V-language). Third, S-language speakers should use more compact structures that encode Cause + Manner in the verb and Path outside. In contrast, $\mathrm{V}$-language speakers should distribute information in more varied ways within and across clauses, e.g., using subordination or stringing different verbs in separate clauses. An interaction between Age and Language was also expected. It was predicted that cross-linguistic differences in how much is expressed should be more striking at young ages, as the acquisition of complex syntactic structures, needed to express more information in some languages (particularly in French), should prevent children from expressing more semantic components, even though they might have noticed them. A fourth prediction concerned Path which constitutes a central motion feature (Talmy, 2000) and which might influence density in all languages studied. In particular, vertical motion should attract denser descriptions than boundary crossing, because it might be harder for children to express categorical changes as compared to gradual changes. Vertical motion descriptions may therefore also attract more complex syntactic structures, especially in French. As for Manner, no particular hypothesis was considered in this paper for reasons of space, and it is therefore only explored qualitatively in the 'Results' section.

\section{Methodology}

Descriptions of caused motion events were systematically elicited from all participants by means of the same animated cartoons.

\section{Participants}

Participants were native speakers of English, German, or French. ${ }^{2}$ Adult participants and children's parents answered a questionnaire ensuring that they were monolinguals and/or had had no substantial exposure to other languages, and that none had cognitive/language problems. A total of 468 participants took part in the study, i.e., 156 participants in each language, including 24 adults, 12 children aged three, and 24 children in five other age groups (approximately four, five, six, eight, and ten years) (cf. Table 1). The smaller number of three-year-olds was due to some difficulties in finding children of this age in schooling contexts, particularly in Great Britain and Germany, where they are rarely sent to preschool. To ensure identical

\footnotetext{
${ }^{2}$ All participants also performed other tasks, including describing voluntary motion events (data analyzed in another paper in progress).
} 
Table 1. Participants

\begin{tabular}{|c|c|c|c|c|c|c|c|c|}
\hline & & Age 3 & Age 4 & Age 5 & Age 6 & Age 8 & Age 10 & Adults \\
\hline \multirow{3}{*}{ English } & range & $2 ; 11-3 ; 6$ & $3 ; 6-4 ; 5$ & $4 ; 6-5 ; 5$ & $5 ; 10-6 ; 5$ & $7 ; 6-8 ; 9$ & $9 ; 6-10 ; 6$ & n.a. \\
\hline & gender & $7 f / 5 m$ & $12 \mathrm{f} / 12 \mathrm{~m}$ & $12 f / 12 m$ & $12 \mathrm{f} / 12 \mathrm{~m}$ & $12 \mathrm{f} / 12 \mathrm{~m}$ & $12 f / 12 m$ & $12 f / 12 m$ \\
\hline & $\mathrm{N}$ & 12 & 24 & 24 & 24 & 24 & 24 & 24 \\
\hline \multirow[t]{3}{*}{ German } & mean & $3 ; 5$ & $4 ; 5$ & $5 ; 5$ & $6 ; 1$ & $8 ; 6$ & $10 ; 7$ & n.a. \\
\hline & gender & $6 f / 6 m$ & $13 \mathrm{f} / 11 \mathrm{~m}$ & $12 \mathrm{f} / 12 \mathrm{~m}$ & $12 \mathrm{f} / 12 \mathrm{~m}$ & $12 \mathrm{f} / 12 \mathrm{~m}$ & $12 \mathrm{f} / 12 \mathrm{~m}$ & $13 \mathrm{f} / 11 \mathrm{~m}$ \\
\hline & $N$ & 12 & 24 & 24 & 24 & 24 & 24 & 24 \\
\hline \multirow[t]{3}{*}{ French } & mean & $3 ; 2$ & $4 ; 5$ & $5 ; 3$ & $6 ; 4$ & $8 ; 6$ & $10 ; 3$ & n.a. \\
\hline & range & $2 ; 11-3 ; 10$ & $3 ; 10-4 ; 10$ & $4 ; 11-5 ; 10$ & $5 ; 9-6 ; 9$ & $7 ; 9-8 ; 9$ & $9 ; 2-11 ; 8$ & n.a. \\
\hline & gender & $7 f / 5 m$ & $12 \mathrm{f} / 12 \mathrm{~m}$ & $12 f / 12 m$ & $12 \mathrm{f} / 12 \mathrm{~m}$ & $11 \mathrm{f} / 13 \mathrm{~m}$ & $14 f / 10 m$ & $12 f / 12 m$ \\
\hline
\end{tabular}


testing conditions at all ages, it was decided to test fewer children at this age, rather than more at home.

\section{Materials}

Participants saw short animated cartoons showing a human agent displacing objects in short scenarios comprising a beginning, a central motion event (hereafter 'target event'), and an ending. The target event involved the following features: the agent moved along a certain Path (UP, DOWN, INTO, ACROSS), displacing an object in a certain manner (by PUSHING or PULLING it, C-Manner) such that this object moved in a certain manner (ROLLING or SLIDING, O-Manner) along the same Path as the agent. The crossing of these features resulted in 16 combinations: Path $(4) \times \mathrm{C}$-Manner (2) $\times$ O-Manner (2). To ensure that results could be generalized beyond a single item, each combination was shown in two different exemplars, both showing different objects being displaced with different backgrounds and grounds (resulting in a total of 32 test items). Two remaining components were held constant in all test items: the causal relation between agent and object (CAUSE), and the agent's Manner of motion (walking or A-Manner). All subjects saw all items, presented in one of four fixed random orders to which participants were randomly assigned. 'Appendix 1' summarizes all item features and 'Appendix 2' illustrates two items. Table 2 shows the five motion components that could be expressed (in addition to motion per se, not coded as such).

Eight additional items were also shown (not analyzed below): an initial training item familiarized participants with the procedure; and seven distractors interspersed among target items (one every block of four test items) diverted their attention from the goal of the study. Distractors also showed caused motion events but differed from test items by virtue of the fact that agent and patient entities were all inanimate (e.g., a ball rolls into a pile of dice that falls down).

\section{Procedure}

Participants were seen individually in a quiet room at their school (children) or university (adults). The entire session was audiotaped. Testing took place in Paris (French sample), in Munich (German sample), and in Cambridge or Milton Keynes (English sample). Participants were shown the cartoons one by one and were asked to say what happened at the end of each. With the training item only, the

Table 2. Types of Information that Could Be Selected for Expression

\begin{tabular}{lll}
\hline Abbreviation & Description & Features in stimuli \\
\hline Cause & Cause & $\begin{array}{c}\text { Causal relation between } \\
\text { Agent and Object }\end{array}$ \\
\hline A-Manner & Manner of Agent's motion & WALK \\
\hline O-Manner & Manner of Object's motion & ROLL, SLIDE \\
\hline C-Manner & Manner of Cause & PUSH, PULL \\
\hline Path & Agent's action causing object's motion & \\
\hline
\end{tabular}


experimenter probed participants further if necessary to ensure that all of them minimally noticed and were able to mention the manipulated motion components. This way, all participants started the task with the same information, irrespective of other factors (language, age, inter-individual variation). After the training item, the experimenter did not intervene with any specific prompts, except to invite the children to get started ("Go ahead") and/or to continue their descriptions (e.g., encouragements such as "uh hum", and general questions such as "And then?"). This procedure allowed continuity in the children's speech flow and ensured that the experimenter did not influence the motion components they chose to express.

Adults and primary-school children had to imagine that they were addressing a 'naive' interlocutor who had not seen the cartoons and that they would have to say what happened based on the audio-recording. Preschool children were introduced to a doll that had been blindfolded and was placed behind the computer screen. Children were invited to tell her everything that happened because she could not see. This procedure ensured that they produced comprehensive responses with only few vague deictic references.

\section{Coding}

The analyses focus on the part of the response that described the target event (hereafter 'target responses'). ${ }^{3}$ The coding was based on the clausal level and responses were therefore first segmented into clauses. A clause was defined as the expression of a proposition minimally containing a verb (except for some verbless labelings), including mostly inflected forms, infinitives, and gerunds. Responses could involve a sentence containing a single clause (21) or a sentence containing more clauses with subordination (22), coordination (23), or juxtaposition (24).

(21) He was pushing the toy car on top of the sand hill. (E0610)

(22) Popi il est monté sur le toit en transportant un sac de tuiles. (FAD19) 'Popi he ascended (on) the roof, carrying a bag of tiles.'

(23) Der Popi der geht über die straße und schiebt den korb. (G0816) 'Popi he crosses the street and shoves the basket.'

(24) He's pushing it. He must cross it. (E0312)

Most target responses (94\% in German, 90\% in English, 75\% in French) consisted of one sentence comprising either a single clause (21) or a matrix clause with one or more subordinate clauses (22). When responses contained several juxtaposed and/or coordinated clauses (23-24), only one was selected as the 'main target response', and others were considered as 'potential target responses' (but see section 'Response architecture' below, in which both main and potential targets are analyzed together). Selection in these cases was based on a number of strict criteria. Relative 'richness' was predominant and by far the most frequent criterion used (between $78 \%$ and $85 \%)$, i.e., one response contained more motion components than the other(s) and was therefore semantically the richest response. For example, in (25) each of the two coordinated clauses could constitute a response by itself, but the first one (main target response) expresses two components (tirer 'to pull' = Cause + C-Manner) and is therefore richer than the second one, which expresses only one component

\footnotetext{
${ }^{3}$ Cases of 'No Response' were infrequent $(<1 \%$ overall) and were left out of all calculations.
} 
(rentrer 'to enter' = Path). Among the remaining responses, some contained two clauses which were equally rich. In these cases, additional criteria were used. For example, when one clause expressed Path and the other Manner, priority was given to Path, a more crucial defining feature of motion (cf. Talmy, 2000).

(25) Donc là Popi il tire [C + C-Manner] une chaise en plastique (Main) et puis il rentre $[\mathrm{P}]$ dans la grotte (Potential). (FAD19)

'So there Popi he pulls a plastic chair and then he enters in the cave.'

After systematic clausal segmentation of responses and assignment of 'target' versus 'potential' status whenever necessary, each clause was coded in multiple ways (minimally 15 coded fields per clause and a total of 45 fields per response) that took into account how many and which motion components were expressed, as well as how they were encoded within the clause (verb vs. other devices) or organized across clauses in discourse (e.g., with or without subordination).

Examples of the coding are shown below. English (26) and German (27) show the combination of Cause with some type of Manner (PUSH/PULL or ROLL/SLIDE) in the verb and Path in other devices. Note that, in our coding, Talmy's strict definition of 'satellites' was enlarged to include all devices other than the main verb root that contribute to motion expression (particles, prepositions, adverbials, gerunds), hence 'other devices'. The French example (28) displays the reverse distribution, expressing Path in the main verb (traverser 'to cross') and Cause + Manner in a peripheral gerund (en tirant 'by pulling'). Verbs such as put and take (29) were coded as expressing only a caused change of location but no other information. Similarly, general verbs such as to go (cf. example (31) below) were considered to be neutral, expressing only motion per se but no additional specific motion information. For each component type expressed, participants could combine different dimensions of this information within the same utterance, e.g., two dimensions of Path are expressed in (30): vertical direction ( $u p$ ) and goal (to the top). Since these cases were rare, only component types were calculated in the analyses.

(26) Hoppy pulled [V = Cause $+\mathrm{C}-\mathrm{Man}$ ] the rocking horse across [Other $=$ Path] the road. (E1004)

(27) Er rollt [V = Cause + O-Man] einen großen Schwimmball den Hügel hinunter [Other $=$ Path $].($ G1023)

'He rolls a big beach ball down the hill.'

(28) Popi traverse [V = Path] la route mouillée en tirant [Other = Cause + C-Man] sa poussette. (F0801)

'Popi crossed the wet road while pulling his pram.'

(29) He took [V = Cause] the chair into [Other = Path] the house. (E0524)

(30) Hoppy pushes [V = Cause $+\mathrm{C}$-Man] the swimming ring up [Other $=$ Path] to the top [Other $=$ Path] of the roof. (E1024)

Clausal segmentation and coding were done by several coders, based on a detailed coding manual. The manual clearly defined Path and Manner and provided detailed examples and criteria for all types. Syntactic packaging involved the use of particular devices marking subordination (relative pronoun, gerund verb form, connective such as while) and coordination (e.g., and, then) or the absence thereof (juxtaposition). All the coding was clearly illustrated in the manual. If any part of the coding 
presented any discrepancy among coders, the entire response was considered problematic and to be discussed until a consensus could be reached among all coders. Once finished, the coding was checked again by two new coders who identified and resolved the few remaining coding disagreements. From the beginning, segmentation was straightforward and presented no coding difficulties, resulting in high inter-judge reliability (99\%). Reliability was also high for the coding of target versus potential target responses (97\%), and of syntactic packaging (93\%), as well as for the coding of event properties, despite a slightly lower score (89\%).

\section{Results}

Results focus on four dimensions of responses: number of component types expressed ('density'); the particular components expressed within each response ('focus'); the distribution of expressed components in verbs versus other devices ('information locus'); and in different structures ('response architecture').

Two different ANOVAs were performed, one on response density and the other on response architecture. In each case, a preliminary ANOVA showed no effect of gender or interactions between this factor and other factors. Gender was therefore ignored in further analyses. Results were considered significant if the probability level did not exceed .05. ${ }^{4}$ For each ANOVA, type-1 and type- 2 analyses were performed (henceforth F1 and F2).

\section{Overall mean response density}

For each response, density corresponded to the total number of different component types expressed among those of Table 2. Examples (31-34) show that density could range from 0 (no specific motion information expressed) to 5 (all components expressed).

(31) Density 0: Il va là. (F0316)

'He goes there.'

(32) Density 1: Y avait Bobi qui a traversé [Path] la rue avec un cheval de bois. (F0512)

'There was Bobi who crossed the street with a wooden horse.'

(33) Density 3: Da zieht [Cause + C-Man] er den Sack auf [Path] den Sandberg hoch [Path].

(G1007)

Lit: 'There pulls he the bag onto the sandhill up.'

(34) Density 5: Popi grimpe [A-Man + Path] sur la dune, en poussant [Cause + C-Man] devant lui la bouée qui tourne [O-Man] dans le sens inverse des aiguilles d'une montre. (FAD16)

'Popi climbs up on the sand dune, pushing in front of him the swimming ring that turns in an anti-clockwise direction.'

An ANOVA was run on mean response density with two between-subject factors (language, age) and one within-subject factor (path). The results show significant

\footnotetext{
${ }^{4}$ Partial squared eta values $\left(\eta^{2}\right)$ are reported since our ANOVA designs comprised both independent and non-independent cells (across and within subjects) (Brown, 2008).
} 
effects of language, age, and path on response density. We turn to each of these effects below.

As predicted, and as shown in Figure 1, language had a significant effect on overall mean response density $\left(F 1(2,447)=93.41, \quad p<.001, \quad \eta^{2}=0.29 ; \quad F 2(2,56)=1398.27\right.$, $p<.001)$. Paired comparisons show that language differences were all significant, with the highest density in German and the lowest in French: Ger $>$ Eng $(F 1(1,298)=4.01$, $\left.p=.0435, \quad \eta^{2}=0.013 ; \quad F 2(1,28)=2606.98, \quad p<.001\right), \quad$ Ger $>$ Fre $\quad(F 1(1,298)=170.46$, $\left.p<.001, \eta^{2}=0.36 ; F 2(1,28)=1797.62, p<.001\right)$, Eng $>$ Fre $(F 1(1,298)=104.31, p<.001$, $\left.\eta^{2}=0.26 ; F 2(1,28)=51.19, p<.001\right)$.

A significant age effect was also observed both overall $(F 1(6,447)=56.25, p<.001$, $\left.\eta^{2}=0.43 ; F 2(6,168)=922.96, p<.001\right)$ and within each language (English $F 1(6,149)=$ $15.44, \quad p<.001, \quad \eta^{2}=0.38 ; \quad F 2(6,168)=365.19, \quad p<.001 ; \quad$ German $F 1(6,149)=17.77$, $p<.001, \eta^{2}=0.42 ; F 2(6,168)=450.18, p<.001$; French $F 1(6,149)=31.33, p<.001, \eta^{2}=$ $0.56 ; F 2(6,168)=271.39, p<.001)$, showing an increase in density from five years on, but no changes before that age. As predicted, language and age also interacted $\left(F 1(12,447)=4.70, \quad p<.001, \quad \eta^{2}=0.11 ; F 2(12,336)=70.81, p<.001\right) . \quad$ A qualitative description of Figure 1 indicates that density did not vary across languages in the adult data, but seems to be higher in German and English than in French at all ages in the child data. Figure 1 further indicates that density appears to be higher in German than in English at ages five and eight. Finally, density increased in German up to age eight, but continued to increase thereafter in English and French.

As also expected, path had an effect on mean response density both overall ( $F 1$ $\left.(3,1341)=32.01, p<.001, \eta^{2}=0.07 ; F 2(3,28)=7.26, p=.001\right)$ and within each language group (English $F 1(3,447)=23.81, p<.001, \eta^{2}=0.14 ; F 2(3,28)=3.53, p=.087$; German $F 1(3,447)=4.71, p=.0039, \eta^{2}=0.03 ; F 2(3,28)=5.72, p=.0035$; French $F 1(3,447)=9.53$, $\left.p<.001, \eta^{2}=0.06 ; F 2(3,28)=9.12, p<.001\right)$. Further comparisons show that density was higher with vertical motion (UP + DOWN) than with boundary crossing (INTO + ACROSS). This advantage of vertical motion was found both overall $(F 1(1,447)=90.02$, $\left.p<.001, \eta^{2}=0.17 ; F 2(1,28)=21.14, p=.0035\right)$ and within each language (English $F 1$ $\left.(1,149)=49.39, p<.001, \eta^{2}=0.25 ; F 2(1,28)=9.08, p=.0053\right) ;$ German $(F 1(1,149)=$ $\left.10.82, p<.001, \eta^{2}=0.07 ; F 2(1,28)=15.46, p<.001\right)$; French $F 1(1,149)=29.98, p<.001$, $\left.\eta^{2}=0.17 ; F 2(1,28)=24.49, p<.001\right)$. Significant interactions were also found between language and path $\left(F 1(6,1341)=3.45, p=.0023, \eta^{2}=0.02 ; F 2(6,56)=5.12, p=.0001\right)$, as well as between language, age, and path $\left(F 1(36,1341)=2.62, p<.001, \eta^{2}=0.066 ; F 2\right.$ $(36,336)=4.69, p<.001)$. Figure 2 shows mean density as a function of these three factors. A qualitative description of Figure 2 shows that, in German and English, variation in response density as a function of path was more frequent among younger children, and decreased or disappeared among older participants. In contrast, variation occurred at all ages in French, a finding which might explain the three-way interaction.

\section{Focus and locus of information: qualitative analyses}

Figure 3 shows motion components expressed in the verb root and in other devices by each age group within each language. Descriptive analyses examined which components were expressed (focus) and where in the response (locus). To compare the relative salience of components, all Manner expressions (C-Manner, O-Manner, A-Manner) were grouped together into a single Manner category $(\mathrm{M})$.

With respect to focus, in all three languages, Cause was most systematically encoded and often combined with other components, resulting in CPM responses. This 


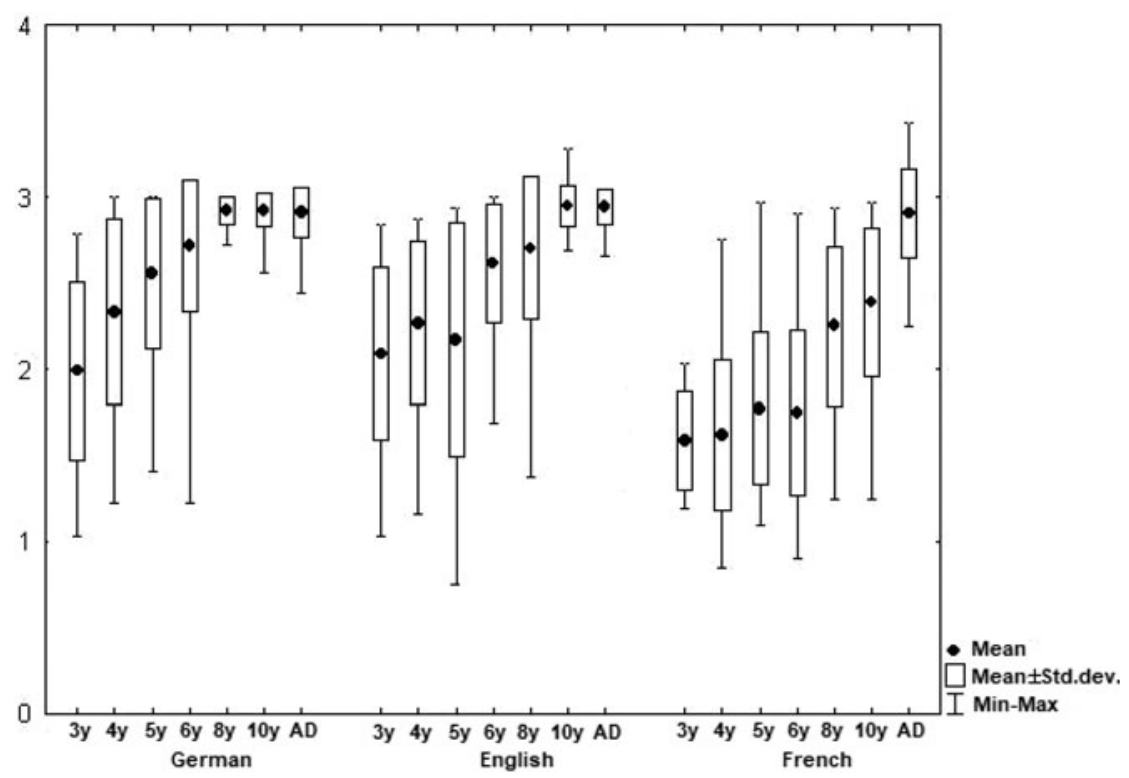

Figure 1. Mean response density as a function of Language and Age.

combination was predominant in English (70\%) and in German (76\%). It occurred much less frequently in French, (34\%), where a variety of different combinations were also found, e.g., expressing Path only (21\%), CM (24\%), CP (12\%), and occasionally both СM and OM (rare in English and German). СРM responses increased with age, resulting in the increasing semantic density reported above, but they also showed different developmental progressions across languages: CPM corresponded to more than half of the responses from age four on in German, and were predominant from age six on in English, but only from ten years on in French, where they remained less frequent than in the other languages, even for the adults.

These findings are likely to result from our data on locus: English and German showed a striking complementary distribution encoding predominantly $\mathrm{CM}$ in the verb root (78\% and 79\%, respectively) and Path in other devices (83\% and $93 \%)$. In sharp contrast, French responses showed fewer CM verbs (42\%) and more variation at both loci, including the frequent absence of any motion-relevant information in other devices (56\%). In English and German, CM verbs increased gradually from age three on. A few other verb types occurred, such as general motion verbs (e.g., to go, to take in 35-37), while other devices mostly expressed Path, and increasingly so with age (e.g., to push up). Devices not expressing any motion information were most frequent among young children and decreased with age in both languages, but this decrease occurred earlier in German than in English.

(35) He's going [0] into the cave with the chair. (E0302)

(36) Der Popi hat den Stuhl in die Scheune getan [Cause]. (G0420)

'Popi has done the chair in the shed.'

(37) He took [Cause] his rocking horse across the road. (E0506) 

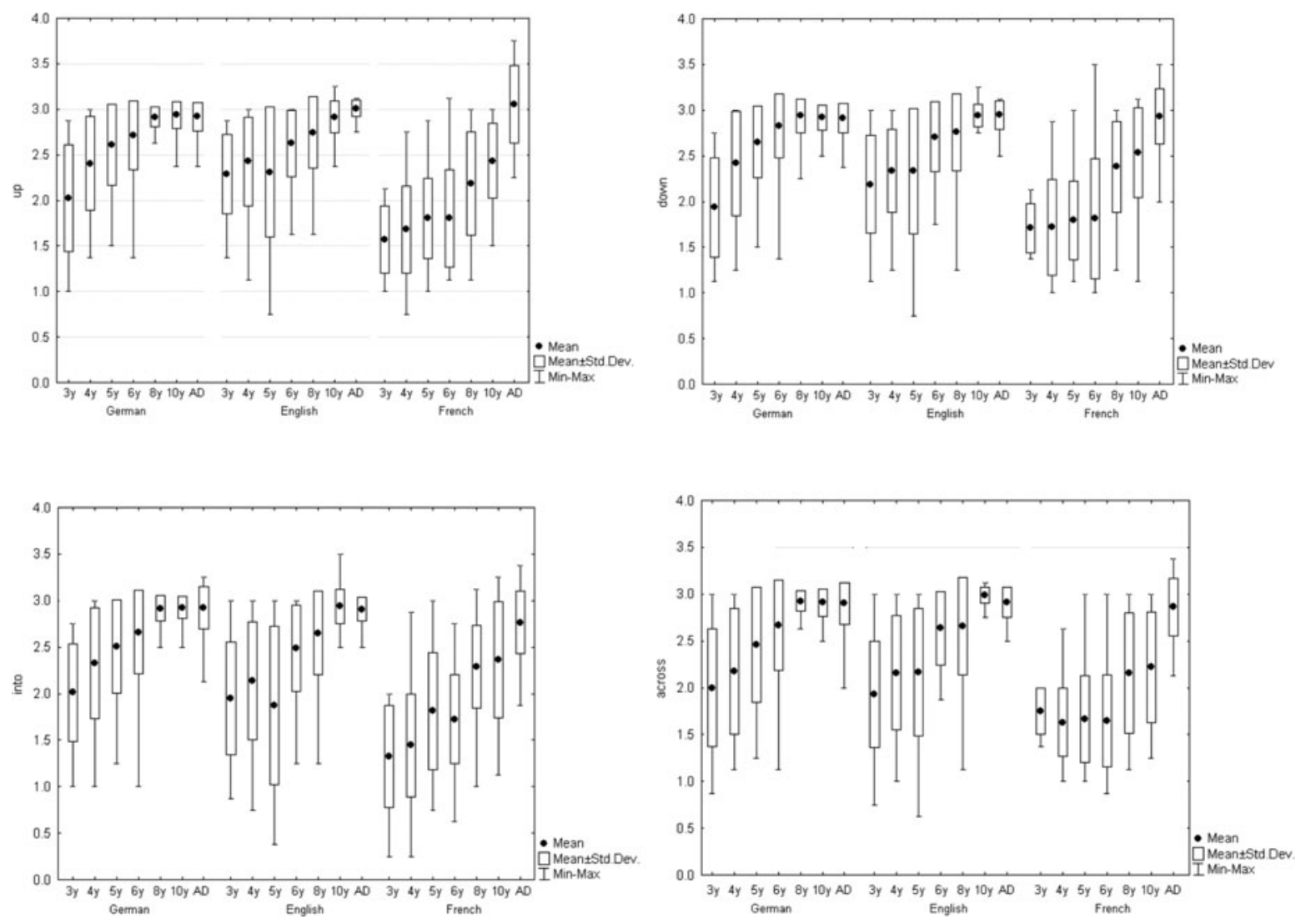
German

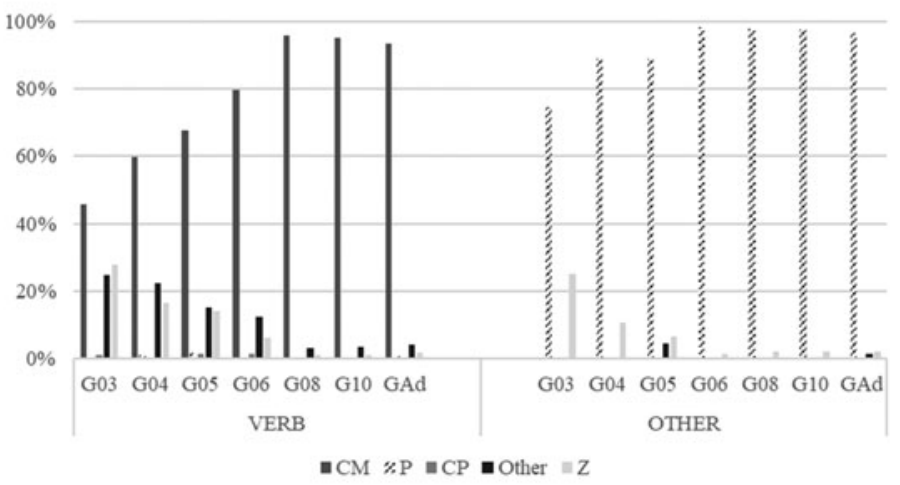

English

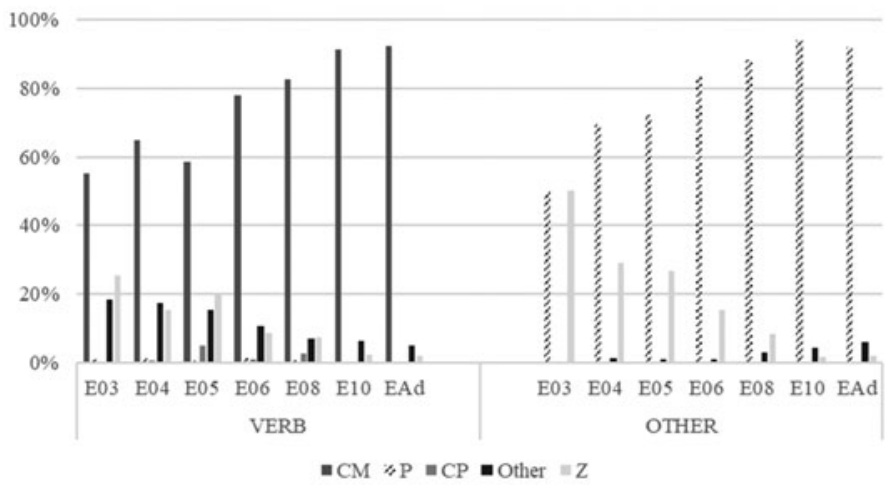

French

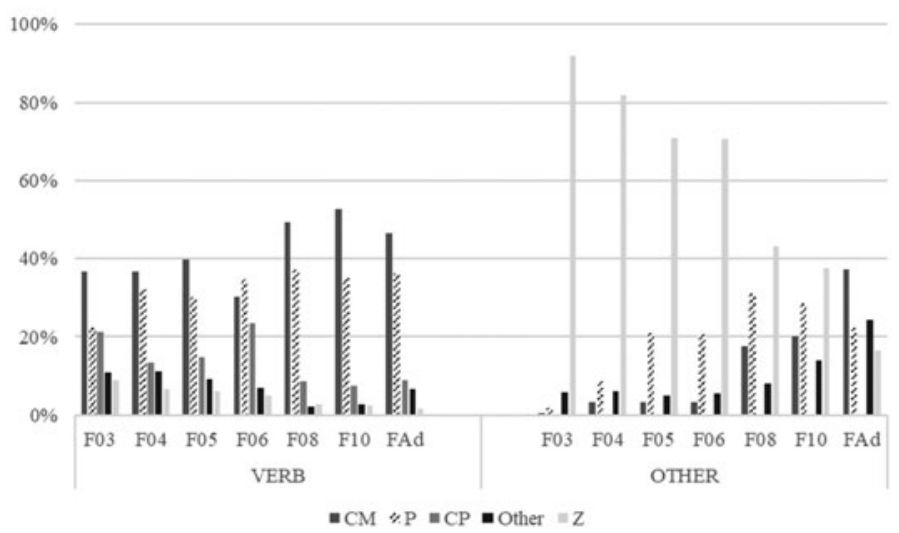

Figure 3. Percentages of component types expressed in main verb roots vs. other devices. 
French verbs were more varied at all ages, including CM verbs (Il pousse la valise 'He pushes the suitcase'), but also P (38) and CP verbs (39), as well as a number of other less frequent verb types. Other devices containing no motion information were predominant among French children in all age groups, but especially before six years (39), thereafter decreasing until adult age. This decrease was accompanied by an increase in other devices expressing P (40), CM (41), and several other combinations (as in verbs).

(38) Popi traverse [Path] la route de droite à gauche en faisant rouler une roue de charrette devant lui. (FAD14)

'Popi crosses the road from right to left while making a cartwheel roll in front of him.'

(39) Il a monté, monté, monté [C + Path] le cadeau. (F0503)

'He has ascended, ascended, ascended [transitive] the present.'

(40) Popi a fait rouler la brouette de haut en bas [Path] de la colline. (F0815)

'Popi has made the wheelbarrow roll from the top to the bottom of the hill.'

(41) Popi monte le toit en tirant [C + C-Man] sa voiture. (F0801)

'Popi ascends the roof while pulling his car.'

\section{Response architecture}

A final set of analyses examined the architecture of participants' responses, this time including both main and potential target responses. The aim was to observe the different structures used across languages to encode caused motion information, assuming that this information should be more frequently encoded in single clauses in German and English than in French. Responses were coded along two dimensions: whether motion information was compactly encoded within a single clause (tight) vs. distributed across more clauses (loose); and whether they contained subordination (complex) or not (simple). Consequently, responses fell into four types, illustrated in (42-45): (1) Tight Simple (TS) if all expressed information relevant to the target event was encoded within one clause; (2) Tight Complex (TC) if information was expressed within a single sentence comprising one or more subordinate clauses; (3) Loose Simple (LS) if information was distributed over several juxtaposed or coordinated clauses; and (4) Loose Complex (LC), a residual category when information was distributed over several juxtaposed or coordinated clauses at least one of which included subordination. Note that we included all responses in our architecture analysis, in contrast to Allen et al. (2007), who only included 'complete' $\mathrm{M}+\mathrm{P}$ responses. We could not restrict our analysis to complete responses (i.e., density 5), as these were highly infrequent in the database, and such sampling would therefore not have been representative of the data. The larger inclusion of responses allowed us to determine the extent to which variation in syntactic packaging occurs, irrespective of the content expressed.

(42) TS: He's rolling the ball down the mountain. (E0413)

(43) TC: Il a poussé le ballon qui a roulé jusqu'en bas de la colline. (F0604) 'He pushed the balloon that rolled all the way to the bottom of the hill.'

(44) LS: Il a poussé le panier et il a traversé la route. (F0417) 'He pushed the basket and he crossed the road.' 
(45) LC: Popi il descend la colline avec une brouette jaune et puis il marche pour la faire rouler. (F1022)

'Popi he descends the hill with a yellow wheelbarrow and then he walks to make it roll.'

A new ANOVA was carried out on TS responses (at the center of our predictions) with language and age as between-subject factors and path as a within-subject factor. Results show significant effects of language $\left(F 1(2,447)=238.39, p<.001, \eta^{2}=0.52 ; F 2\right.$ $(2,56)=2666.15, p<.001)$, age $\left(F 1(6,447)=11.23, p<.001, \eta^{2}=0.13 ; F 2(6,168)=\right.$ $87.51, p<.001)$, and path $\left(F 1(3,1341)=9.03, p<.001, \eta^{2}=0.02 ; F 2(3,28)=7.23\right.$, $p=.001)$.

Figure 4 displays mean TS responses by language and age. Language contrasts show more TS responses in German and English than in French (Ger $>$ Fre: $F 1(1,298)=$ 450.90, $p<.001, \eta^{2}=0.60 ; F 2(1,28)=3422.57, p<.001$; Eng $>$ Fre: $F 1(1,298)=212.77$, $\left.p<.001, \eta^{2}=0.42 ; F 2(1,28)=184.94, p<.001\right)$, and more in German than in English (Ger $>$ Eng: $\left.F 1(1,298)=20.85, p<.001, \eta^{2}=0.07 ; F 2(1,28)=4214.15, p<.001\right)$. These language differences seem to occur at all ages. Age and language also interacted significantly $\left(F 1(12,447)=7.72, p<.001, \eta^{2}=0.17 ; F 2(12,336)=75.82, p<.001\right)$. In particular, age had an effect on TS responses in French $(F 1(6,149)=16.99, p<.001$, $\left.\eta^{2}=0.41 ; F 2(6,320)=9.66, p<.001\right)$, but not in English and German, where TS responses were predominant at all ages. As for path, the overall comparison between Path types shows significantly more TS responses for vertical motion (UP + DOWN) than for boundary crossing (INTO + ACROSS) $\left(F 1(1,447)=7.99, p=.005, \eta^{2}=0.017 ; F 2\right.$ $(1,28)=5.85, p=.02)$. However, this difference in Path types is not significant in any of the individual languages. In contrast to density, then, there seem to be no clear Path effects within languages with respect to response architecture.

Table 3 provides further qualitative information about the types of response architecture that were found. A quick glance at Table 3 shows that architecture clearly varied across languages. Not only were TS responses most frequent in English and German at all ages (cf. results reported above), but this qualitative look also shows that TC responses were more frequent in French and increasingly so with age.

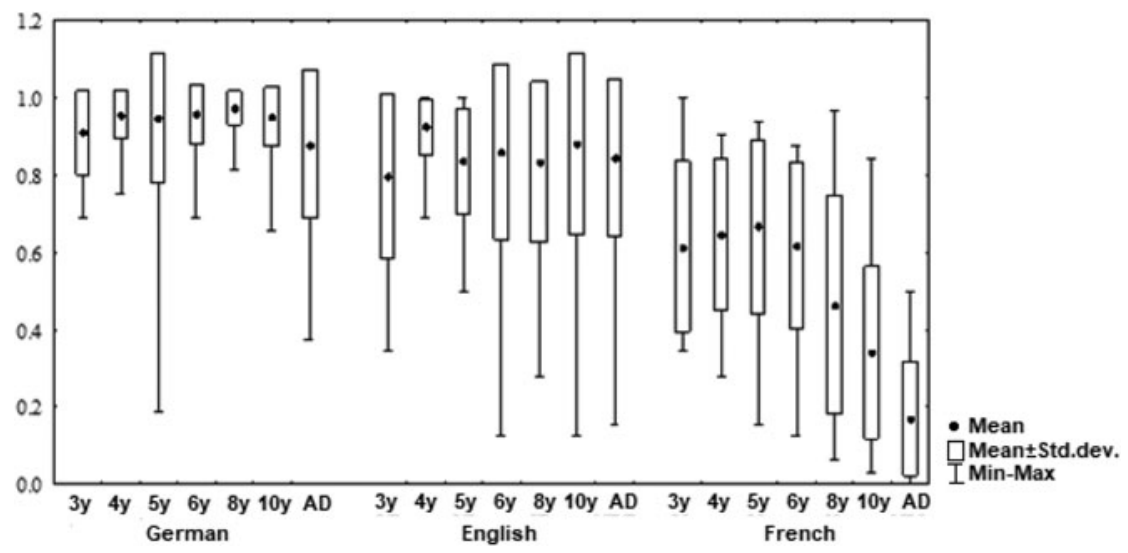

Figure 4. Mean Tight-Simple (TS) responses as a function of Age and Language. 
Table 3. Percentages of Architecture Types out of All Responses (Tot) by Age and Language

\begin{tabular}{|c|c|c|c|c|c|c|c|c|c|c|c|c|c|c|c|}
\hline \multirow{2}{*}{ Age } & \multicolumn{5}{|c|}{ German } & \multicolumn{5}{|c|}{ English } & \multicolumn{5}{|c|}{ French } \\
\hline & TS & $\mathrm{TC}$ & LS & $\mathrm{LC}$ & Tot & TS & $\mathrm{TC}$ & LS & $\mathrm{LC}$ & Tot & TS & TC & LS & LC & Tot \\
\hline $3 y$ & $94 \%$ & 0 & $6 \%$ & 0 & 372 & $93 \%$ & 0 & $7 \%$ & 0 & 329 & $62 \%$ & $4 \%$ & $30 \%$ & $4 \%$ & 380 \\
\hline $4 y$ & $96 \%$ & 0 & $4 \%$ & 0 & 766 & $96 \%$ & $1 \%$ & $3 \%$ & 0 & 739 & $65 \%$ & $8 \%$ & $27 \%$ & $1 \%$ & 762 \\
\hline $5 y$ & $95 \%$ & 0 & $5 \%$ & 0 & 767 & $86 \%$ & $2 \%$ & 11 & $1 \%$ & 743 & $67 \%$ & $7 \%$ & $23 \%$ & $3 \%$ & 765 \\
\hline $6 y$ & $96 \%$ & 0 & $4 \%$ & 0 & 768 & $89 \%$ & $1 \%$ & $9 \%$ & $1 \%$ & 744 & $62 \%$ & $12 \%$ & $23 \%$ & $3 \%$ & 766 \\
\hline $8 y$ & $97 \%$ & 0 & $3 \%$ & 0 & 768 & $84 \%$ & $2 \%$ & $13 \%$ & $1 \%$ & 764 & $46 \%$ & $33 \%$ & $17 \%$ & $4 \%$ & 766 \\
\hline $10 y$ & $95 \%$ & 0 & $5 \%$ & 0 & 767 & $88 \%$ & $3 \%$ & $7 \%$ & $2 \%$ & 768 & $34 \%$ & $43 \%$ & $16 \%$ & $6 \%$ & 767 \\
\hline Ad & $88 \%$ & 1 & $11 \%$ & 0 & 765 & $84 \%$ & $4 \%$ & $10 \%$ & $4 \%$ & 766 & $17 \%$ & $59 \%$ & $12 \%$ & $11 \%$ & 766 \\
\hline
\end{tabular}


Most variation in response architecture occurred in French, both within and across ages. TS responses did not vary with age in German, while they initially increased with age in English until five years, but not thereafter. As regards French responses, they involved both TS and LS, mostly among young children, but thereafter TS responses decreased from six years on until adulthood, due to a clear increase in TC responses.

\section{Summary of results}

Our analyses show the following expected results. First, density increases with age in all three languages, and Path impacts density at all ages and in all languages (UP, DOWN > INTO, ACROSS). Second, at all ages, English and German responses frequently contained all three main components $(\mathrm{CPM}=$ Cause + Path + Manner $)$ in a complementary distribution ( $\mathrm{CM}$ in the verb, $\mathrm{P}$ in other devices). At all ages, French responses contained fewer $\mathrm{CM}$ verbs and either no motion information at all outside the verb, or more varied components, resulting in a lower overall proportion of CPM responses and hence lower density than in the other languages. Finally, with respect to response architecture, most responses consisted of one-clause sentences (TS) at all ages in English and German, but not in French, where these responses were least frequent at all ages and decreased with age, while subordination (TC) increased. In contrast to density, Path did not impact TS responses in any of the three languages examined.

\section{Discussion}

This study investigated the expression of caused motion by children and adults in English, German, and French. To our knowledge, it is the largest detailed developmental (seven age groups from three years to adulthood) and cross-linguistic study (three languages of two different typological properties) on the expression of caused motion (but cf. Furman et al., 2014; Ji et al., 2011a, 2011b). The main reasons for studying the expression of caused motion were three-fold: (1) whereas many studies have looked at the expression of voluntary motion and placement events, little is still known about caused motion, and this study therefore fills a gap; (2) describing caused motion implies many components from which to choose. It therefore naturally creates a different condition from voluntary motion and placement events for revealing typological patterns, as speakers may be out of their 'comfort zone' when trying to express this much information. Along similar lines, Özçalişkan (2015) created such circumstances in a more artificial way, asking V-language speakers to use Manner verbs; and (3) caused motion situations are very frequent in the environment of all children, and therefore constitute a natural way of eliciting further information about the lexicalization and syntactic patterning of typologically different languages.

Our aim was to further our understanding of the development of caused motion expression in S- vs. V-languages and its implications for the development of motion expression more generally in these two language types. To this end, we examined the effects of age, language, and Path on several aspects of the responses: the number of expressed components (density), the particular components selected for expression (focus), and their distribution within each clause (locus) and across clauses in discourse (architecture). 
We tested the following hypotheses: (1) the number of components expressed should increase with age in all languages; (2) speakers should express more motion components in English and German (S-languages) than in French (V-language); (3) speakers should use mostly tight simple constructions in English and German, but a larger variety of structures including juxtaposition, coordination, and subordination in French; and (4) Path was expected to influence density in all languages. The discussion below considers the role of cognitive development, language-specific features, and specific Paths in determining caused motion expression.

\section{Cognitive and typological factors}

Results showed that the number of expressed components increased with age in all languages, indicating that the main developmental changes occurred from five years onwards. This result supports our first hypothesis. Children in all languages expressed Cause from early on, indicating their understanding of the importance of this information for the task, and their capacity to use appropriate linguistic means to express it. The most striking increase with age concerned responses expressing three components (CPM), mostly because young children used fewer devices outside the verb to express motion information. This result held to some extent in all three languages but was clearly most pronounced in French.

Research examining children's expression of voluntary motion (Harr, 2012; Hickmann \& Hendriks, 2010; Hickmann et al., 2009b) also shows increasing density with age. Furthermore, Allen et al. (2007) similarly report that a considerable number of three-year-olds did not produce Manner + Path responses in Turkish, Japanese, and English. These common patterns across languages presumably reflect children's increasing cognitive abilities in this type of task. Although more research should include other measures of cognitive capacities to test this hypothesis directly, it is highly likely that such capacities play a role in children's growing ability to describe caused motion.

In the present study on caused motion, children had to handle more components (five) than in previous situations about voluntary motion (two: Manner and Path). Increasing semantic density across these different tasks and languages further supports the claim that similar general cognitive abilities may come into play during the development of motion descriptions. However, cross-linguistic differences were also observed at all ages across and within language types (French vs. German and English; German vs. English), showing variable developmental progressions as a result of language particulars. As predicted, response density was higher in German and English than in French, except among adults (whose responses were equally dense across all three languages).

Again, language comparisons in previous studies on voluntary motion also showed that S-languages elicited high-density responses containing both Path and Manner, with an advantage of English over French (Hickmann \& Hendriks, 2010; Hickmann et al., 2009b) and of German over French (Harr, 2012). However, density was also higher in German than in English, where the adult pattern of information distribution (c+ $M$ in the verb, $P$ in other devices) is in place by six years. French showed more variation in expressed information at all ages, and a relatively late decrease in devices outside the verb that did not express any motion information. СPM responses therefore appeared later in French, resulting in a later density increase. $\mathrm{C}$ and $\mathrm{M}$ were often lexicalized in the verb in all languages, and Path tended to be the missing 
information in less dense responses in all languages, but particularly in French. Finally, one-clause responses (TS) were predominant in German and English at all ages, but a striking progression with age was observed in French: LS and TS responses occurred at an early age, followed by increasing TC responses from eight years onwards (cf. also related results in Allen et al., 2007, for Japanese and Turkish). Increasing density and subordination therefore seem related in French, allowing more main motion components to be expressed when subordination is in place.

These results deserve further discussion. First, differences between English and German (both S-framed) cannot be explained by typological features but call for a more detailed analysis of linguistic features in these languages (cf. also Slobin et al., 2011, for another discussion of intra-typological variation with placement verbs in Svs. V-languages). One explanation could lie with the linguistic means available in these languages. In addition to a number of devices that are similar to English (e.g., prepositions, adverbials), German provides more verb-particles (hoch, runter, rüber, hin, her). These particles frequently express Path, whereas English prepositions and adverbials can either express a boundary crossing (into, away) or a general location (in, on). The fact that these linguistic means have a closer syntactic link to the verb may have encouraged their use by German children, and their systematic expression of Path may have increased the overall amount of Path expressed in this language. German also allows double-Path expressions (46), which may have further focused the German child's attention to Path. Such differences show the importance of detailed studies of languages within typological groups and the need to consider the typology in terms of a gradient, e.g., German seems to be relatively more S-framed than English.

(46) Über die Strasse rüber rennen.

'Across the street across run.'

Second, the distribution of information in French was even more diversified than expected. As mentioned in the 'Introduction', predictions are not so clear in the literature for caused motion in V-languages, mostly discussed together with voluntary motion and with explicit predictions concerning voluntary motion (if Path is encoded in the verb, then the co-event must be encoded elsewhere). Our data show responses containing Path verbs (e.g., il monte 'he ascends' (see 47), but also many verbs and causative constructions expressing Cause combined with various other components. This result could be partly due to the task, which invited a heightened focus on Cause. More importantly, although Manner of voluntary motion can be easily relegated to the periphery without impacting information flow, this is less obvious for Cause, given that agentive causation was central in our stimuli, requiring the agent's action be mentioned or easily inferred.

(47) Il monte [Path] le toit en tirant le sac.

'He ascends the roof pulling the bag'.

Third, our coding of Path was quite strict and could have impacted results concerning overall response density, especially in French. For example, in (48), the preposition dans 'in' was coded as locative (no intrinsic change of location). It could be argued that this coding decision underestimated the extent to which Path was expressed in French. However, in the absence of explicit markings in French (e.g., 
such as English in vs. into), such expressions are entirely ambiguous between (static) locative and (dynamic) Path interpretations. As a result, changes of location in French must be inferred from context unless they are explicitly encoded in the verb.

(48) Popi pousse le pneu dans la grotte. (F0803)

'Popi pushes the tire in the cave.'

An additional point concerns the choice of one target response when participants produced more possible responses. English and German responses were typically compact (TS), and their density scores therefore included all expressed information. In French, however, information was frequently distributed over several clauses (LS, LC), only one of which was chosen as the target response (typically the richest one). As a result, even though all components might be mentioned, some were not included in the density scores. Findings concerning response architecture allowed us to complement this possible underestimation of semantic density for French children, showing the increasing role of subordination in the development of French motion expression.

In conclusion, results show a greater and later developmental progression in French than in English or German. This cross-linguistic difference stems from different ways of distributing information. English and German show dense verbs in compact one-clause structures systematically expressing all types of information, thereby presenting children with clear and systematic high-density structures to learn. In contrast, compactly combining multiple types of information is not as easy in French, where children produced more varied responses and did not achieve higher density until they had also acquired more complex structures.

\section{Path effects}

Recall that three event properties were varied in our stimuli, including especially Path in addition to several types of Manners (which were only explored here qualitatively). Our analyses focused on Path, testing the hypothesis that this feature, most essential in Talmy's typology, might impact responses. Indeed, UP/DOWN elicited denser responses than INTO/ACROss in all three languages. This finding suggests that children find it more difficult to combine multiple components with boundary crossing than with vertical motion, perhaps because the former (which implies categorical changes) involves conceptually more complex events than the latter (which implies gradual changes of location). Note that Path differences occurred mainly at young ages in English and German, while they occurred at all ages in French, where devices outside the verb increased at a slower rate. Our hypothesis that the relative complexity of events might also impact response architecture was not borne out. Although significantly more TS responses were found overall with vertical motion events than with the more complex crossing events, this finding was not replicated for any of the individual languages, indicating that this effect corresponded only to a tendency.

\section{Future directions}

This study only examined language production. Further research should address questions about the relation between the linguistic representation of motion events 
and non-verbal event construal. In particular, the present study concerns what Slobin (2003) calls research on 'speaking time' (the time during which linguistically codable dimensions must be accessed and attended to). However, a comprehensive study should also include 'experience time' (the time during which the individual must attend to event properties that are relevant for linguistic encoding) and 'testing time' (the time during which language-specific features affect non-linguistic cognition). Although our results lead to strong conclusions regarding a long-lasting impact of language particulars on motion expression, some questions remain open concerning how speakers might conceptually construe caused motion in different ways.

Some studies (Choi \& Hattrup, 2012; Gennari, Sloman, Malt, \& Fitch, 2002; Hickmann, Engemann, Soroli, Hendriks, \& Vincent, 2017; Papafragou, Hulbert, \& Trueswell, 2008; Richmond, Zhao, \& Burns, 2015) have begun to address these questions using other methodologies, such as a combination of verbal and non-verbal tasks and measures. Non-verbal measures include responses in tasks that do not involve any language input or output (categorization, memory of visual stimuli), accompanied by on-line measures, such as reaction times and eye-tracking, indicating to what particular features of events participants pay attention (eye-gaze) and how long they look at it (gaze duration) during the exploration of visual stimuli. Some also aim at examining the relation between language and motion event representation during the time at which a motion event is presented to the participant, e.g., interference tasks such as syllable repetition, ensuring that participants are not verbalizing their event representations internally. This work is in progress and beyond the scope of the present paper.

\section{Concluding remarks}

Our findings have contributed additional information regarding the expression of caused motion in a V-framed as compared to two S-framed languages. Speakers of each language type frequently encode Cause and Manner of Cause in the verb. In S-languages the verb can be easily combined with Path encoded in other devices at the periphery of the verb. In contrast, in V-languages, more complex syntactic structures are necessary to express all components, resulting in a greater diversification of structures and lexicalization patterns in this language. Our results show the importance of studying the impact of typology through diverse types of motion events, as some aspects of the lexicalization pattern found for French in caused motion differs from the one reported for voluntary motion (cf. also Hickmann \& Hendriks, 2006, for placement verbs). The results also correspond to those of other studies indicating that a simple dichotomy of language types might not be the best way to represent cross-linguistic diversity, and that a continuum would be more suitable.

Our results concerning the acquisition of caused motion show developmental patterns reflecting both general cognitive development and language-specific patterns determined by the particular properties of children's language. The combination of general and language-specific patterns has also been reported by developmental studies on the acquisition of voluntary motion and placement events (Allen et al., 2007; Gullberg, 2011; Hickmann et al., 2009b; Slobin et al., 2011), indicating that both factors have an impact on the expression of motion events in discourse. So far, results suggest that it takes children more time to learn how to encode motion in some languages than in others when describing both voluntary and caused motion. 
Further research is necessary to compare more languages, more varied event types, and more linguistic domains beyond motion expression.

Acknowledgements. The research reported in this paper is part of a French-German research project entitled 'LANGACROSS', which was financially supported by the French and German national funding agencies for research (ANR, DFG). We thank all participants for their cooperation in our study, as well as the Action Editor and two anonymous reviewers for their valuable feedback.

\section{References}

Allen, S., Özyürek, A., Kita, S., Brown, A., Furman, R., \& Ishizuka, T. (2007). Language-specific and universal influences in children's syntactic packaging of Manner and Path: a comparison of English, Japanese, and Turkish. Cognition, 102(1), 16-48.

Aske, J. (1989). Path predicates in English and Spanish: a closer look. In K. Hall, M. Meacham, \& R. Shapiro (Eds.), Proceedings of the fifteenth annual meeting of the Berkeley Linguistics Society (pp. 1-14). Berkeley, CA: The Berkeley Linguistics Society Inc.

Beavers, J., Levin, B., \& Tham, S.-W. (2010). The typology of motion expressions revisited. Journal of Linguistics, 46(2), 331-77.

Bohnemeyer, J., Enfield, N., Essegbey, J., \& Kita, S. (2011). The macro-event property: the segmentation of causal chains. In J. Bohnemeyer \& E. Pederson (Eds.), Event representation in language and cognition (pp. 43-67). Cambridge University Press.

Bowerman, M. (1996). The origins of children's spatial semantic categories: cognitive vs. linguistic determinants. In J. J. Gumperz \& S. C. Levinson (Eds.), Rethinking linguistic relativity (pp. 145-76). Cambridge University Press.

Bowerman, M., \& Choi, S. (2001). Shaping meanings for language: universal and language-specific in the acquisition of spatial semantic categories. In M. Bowerman \& S. C. Levinson (Eds.), Language acquisition and conceptual development (pp. 475-511). Cambridge University Press.

Brown, J. D. (2008). Effect size and eta squared. Shiken: JALT Testing \& Evaluation SIG Newsletter, 12(2), $38-43$.

Choi, S. (2011). Language-specificity of motion event expressions in young Korean children. Language, Interaction and Acquisition (LIA), 2(1), 157-84.

Choi, S., \& Bowerman, M. (1991). Learning to express motion events in English and Korean: the influence of language-specific lexicalization patterns. Cognition, 41, 83-121.

Choi, S., \& Hattrup, K. (2012). Relative contribution of cognition/perception and language on spatial categorization. Cognitive Science, 36, 102-29.

Cowan, N. (2014). Short-term and working memory in childhood. In P. J. Bauer \& R. Fivush (Eds.), The Wiley handbook on the development of children's memory (pp. 202-29). John Wiley Publishers.

Croft, W., Barðdal, J., Hollmann, W., Sotirova, V., \& Taoka, C. (2010). Revising Talmy's typological classification of complex events. In H. C. Boas (Ed.), Contrastive construction grammar (pp. 201-36). Philadelphia/Amsterdam: John Benjamins.

Furman, R., Kuntay, A., \& Özyürek, A. (2014). Early language-specificity of children's event encoding in speech and gesture: evidence from caused motion in Turkish. Language, Cognition and Neuroscience, 29, 620-34.

Gathercole, S. E. (1999). Cognitive approaches to the development of short-term memory. Trends in Cognitive Sciences, 3(11), 410-19.

Gennari, S., Sloman, S., Malt, B., \& Fitch, W. (2002). Motion events in language and cognition. Cognition, 83(1), 49-79.

Gullberg, M. (2011). Language-specific encoding of placement events in gestures. In J. Bohnemeyer \& E. Pederson (Eds.), Event representation in language and cognition (pp. 166-88). Cambridge University Press.

Harr, A.-K. (2012). The impact of language-specific factors in first language acquisition: the expression of motion in French and German (Studies on Language Acquisition). Berlin: Mouton de Gruyter.

Hickmann, M. (2003). Children's discourse: person, space and time across languages. Cambridge University Press. 
Hickmann, M., Engemann, H., Hendriks, H., Soroli, E., \& Vincent, C. (2017). Expressing and categorizing motion in French and English: verbal and non-verbal cognition across languages. In I. Ibarretxe-Antuñano (Ed.), Motion and space across languages and applications (pp. 61-94). Amsterdam: John Benjamins.

Hickmann, M., \& Hendriks, H. (2006). Static and dynamic location in French and English. First Language, 26(1), 103-35.

Hickmann, M., \& Hendriks, H. (2010). Typological constraints on the acquisition of spatial language in French and English. Cognitive Linguistics, 21(2), 189-215.

Hickmann, M., Hendriks, H., \& Champaud, C. (2009a). Typological constraints on motion in French and English child language. In J. Guo, E. Lieven, S. Ervin-Tripp, N. Budwig, K. Nakamura, \& Ş. Özçalışkan (Eds.), Crosslinguistic approaches to the psychology of language: research in the tradition of Dan Isaac Slobin (pp. 209-24). New York: Psychology Press.

Hickmann, M., Taranne, P., \& Bonnet, P. (2009b). Motion in first language acquisition: manner and path in French and English child language. Journal of Child Language, 36, 705-41.

Ibarretxe-Antuñano, I. (2009). Path salience in motion events. In J. Guo, E. Lieven, N. Budwig, S. Ervin-Tripp, K. Nakamura, \& S. Özçalışkan (Eds.), Crosslinguistic approaches to the psychology of language: research in the tradition of Dan Isaac Slobin (pp. 403-14). New York: Psychology Press.

Ji, Y., Hendriks, H., \& Hickmann, M. (2011a). The expression of caused motion events in Chinese and in English: some typological issues. Linguistics, 49(5), 1041-76.

Ji, Y., Hendriks, H., \& Hickmann, M. (2011b). How children express caused motion events in Chinese and English: universal and language-specific influences. Lingua, 121, 1796-819.

Kopecka, A. (2006). The semantic structure of motion verbs in French: typological perspectives. In M. Hickmann \& S. Robert (Eds.), Space in languages: linguistic systems and cognitive categories (pp. 83-101). Amsterdam: John Benjamins.

Kopecka, A., \& Narasimhan, B. (2012). Events of putting and taking: a crosslinguistic perspective (Typological Studies in Language). Amsterdam/New York: Benjamins.

Lloyd, P. (1991). Strategies used to communicate route directions by telephone: a comparison of the performance of 7-year-olds, 10-year-olds and adults. Journal of Child Language, 18(1), 175-89.

Majid, A., Bowerman, M., van Staden, M., \& Boster, J. S. (2007). The semantic categories of cutting and breaking events: a crosslinguistic perspective. Cognitive Linguistics, 18(2), 133-52.

Matsumoto, Y. (2003). Typologies of lexicalization patterns and event integration: clarifications and reformulations. In S. Chiba et al. (Eds.), Empirical and theoretical investigations into language: $A$ Festschrift for Masaru Kajita (pp. 403-18). Tokyo: Kaitakusha.

Naigles, L. R., Eisenberg, A. R., Kako, E. T., Highter, M., \& McGraw, N. (1998). Speaking of motion: verb use in English and Spanish. Language and Cognitive Processes, 13, 521-49.

Narasimhan, B., \& Brown, P. (2009). Getting the INSIDE story: learning to talk about containment in Tzeltal and Hindi. In V. Mueller-Gathercole (Ed.), Routes to language: studies in honor of Melissa Bowerman (pp. 97-130). Mahwah, NJ: Lawrence Erlbaum.

Newcombe, N. S., Uttal, D. H., \& Sauter, M. (2013). Spatial development. In P. Zelazo (Ed.), Oxford handbook of developmental psychology, Vol. 1: body and mind (pp. 564-90). Oxford University Press.

Nys, M., Gyselinck, V., \& Hickmann, M. (2016). The role of visuo-spatial abilities and working memory in the development of children's spatial representation of a virtual route. Paper presented at the European Workshop on Imagery and Cognition (EWIC), Paris-Descartes, 6-8 June. Retrieved from <http:// ewic2016.parisdescartes.fr/>.

Özçalişkan, S. (2015). Ways of crossing a spatial boundary in typologically distinct languages. Applied Psycholinguistics, 36, 485-508.

Özçalişkan, S., \& Slobin, D. I. (1999). Learning how to search for the frog: expression of manner of motion in English, Spanish and Turkish. In A. Greenhill, H. Littlefield, \& C. Tano (Eds.), BUCLD 23 Proceedings (pp. 541-52). Sommerville, MA: Cascadilla Press.

Papafragou, A., Hulbert, J., \& Trueswell, J. (2008). Does language guide perception? Evidence from eye movements. Cognition, 108, 155-84.

Pickering, S. J. (2001). The development of visuo-spatial working memory. Memory, 9(4/6), 423-32.

Richmond, J. L., Zhao, J. L., \& Burns, M. A. (2015). What goes where? Eye tracking reveals spatial relational memory during infancy. Journal of Experimental Child Psychology, 130, 79-91. 
Slobin, D. I. (1996). From 'thought and language' to 'thinking for speaking'. In J. J. Gumperz \& S. C. Levinson (Eds.), Rethinking linguistic relativity (pp. 70-96). Cambridge University Press.

Slobin, D. I. (2003). Language and thought online: cognitive consequences of linguistic relativity. In D. Gentner \& S. Goldin-Meadow (Eds.), Language in mind: advances in the study of language and thought (pp. 157-92). Cambridge, MA: MIT Press.

Slobin, D. I. (2004). The many ways to search for a frog: linguistic typology and the expression of motion events. In S. Strömqvist \& L. Verhoeven (Eds.), Relating events in narrative, Vol. 2: typological and contextual perspectives (pp. 219-57). Mahwah, NJ: Erlbaum.

Slobin, D. I., Bowerman, M., Brown, P., Eisenbeiss, S., \& Narasimhan, B. (2011). Putting things in places: developmental consequences of linguistic typology. In J. Bohnemeyer \& E. Pederson (Eds.), Event representation in language and cognition (pp. 134-65). Cambridge University Press.

Talmy, L. (2000). Towards a cognitive semantics. Cambridge, MA: MIT Press.

\section{Appendix 1}

Properties of the stimuli

\begin{tabular}{|c|c|c|c|c|}
\hline $\begin{array}{l}\text { Manner of Cause } \\
\text { (Manner of Agent's action } \\
\text { causing Object motion) }\end{array}$ & $\begin{array}{l}\text { Displaced object } \\
\text { (Figure) }\end{array}$ & $\begin{array}{l}\text { Manner } \\
\text { of Object } \\
\text { Motion }\end{array}$ & Path & Ground \\
\hline \multirow[t]{2}{*}{ push } & swimming ring & roll & up & roof or sand dune \\
\hline & package & slide & & \\
\hline \multirow[t]{2}{*}{ pull } & toy car & roll & & \\
\hline & bag & slide & & \\
\hline \multirow[t]{2}{*}{ push } & balloon & roll & down & snow or grass hill \\
\hline & suitcase & slide & & \\
\hline \multirow[t]{2}{*}{ pull } & wheelbarrow & roll & & \\
\hline & trunk & slide & & \\
\hline \multirow[t]{2}{*}{ Push } & tire & roll & into & cave or barn \\
\hline & table & slide & & \\
\hline \multirow[t]{2}{*}{ Pull } & shopping trolley & roll & & \\
\hline & chair & slide & & \\
\hline \multirow[t]{2}{*}{ Push } & wheel & roll & across & street or road \\
\hline & apple basket & slide & & \\
\hline \multirow[t]{2}{*}{ Pull } & pram & roll & & \\
\hline & rocking horse & slide & & \\
\hline
\end{tabular}




\section{Appendix 2}

Illustrations of two items

\section{pull-slide-across}

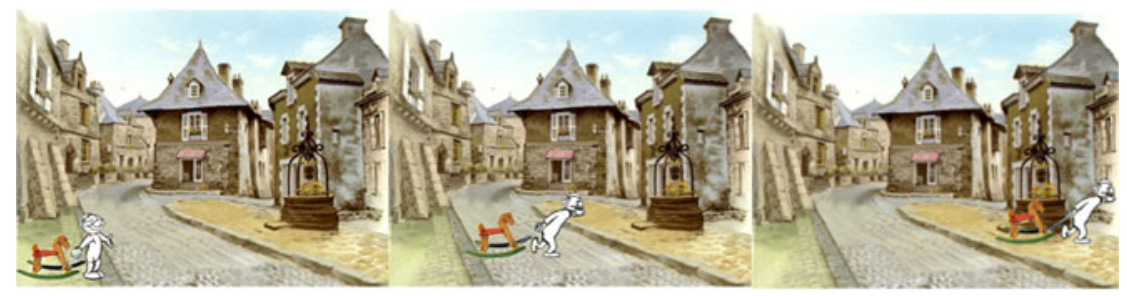

Beginning

$\underline{\text { Target }}$

End

\section{push-roll-up}

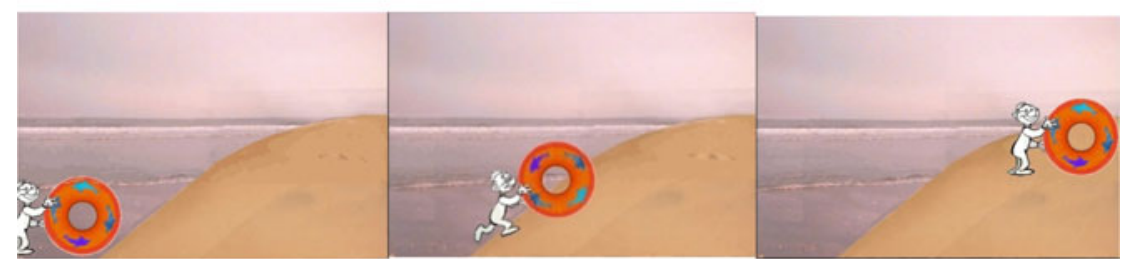

Beginning

$\underline{\text { Target }}$

End

Cite this article: Hickmann M, Hendriks H, Harr A-K, Bonnet P (2018). Caused motion across child languages: a comparison of English, German, and French. Journal of Child Language 45, 1247-1274. https://doi.org/10.1017/S0305000918000168 